\title{
Prevalence of child-directed and general audience marketing strategies on the front of beverage packaging: the case of Chile
}

\author{
Fernanda Mediano Stoltze ${ }^{1,2}$, Joshua O Barker ${ }^{2}$, Rebecca Kanter ${ }^{3}$, Camila Corvalán $^{3}$, \\ Marcela Reyes ${ }^{3}$, Lindsey Smith Taillie ${ }^{1,4}$ and Francesca R Dillman Carpentier ${ }^{2, *}$ \\ ${ }^{1}$ Carolina Population Center, University of North Carolina, Chapel Hill, NC, USA: ${ }^{2}$ School of Media and Journalism, \\ University of North Carolina, CB 3365, Chapel Hill, NC 27599-3365, USA: ${ }^{3}$ Institute of Nutrition and Food \\ Technology (INTA), University of Chile, Santiago, Chile, USA: ${ }^{4}$ Department of Nutrition, Gillings School of Global \\ Public Health, University of North Carolina, Chapel Hill, NC, USA
}

Submitted 30 January 2017: Final revision received 11 July 2017: Accepted 17 August 2017: First published online 2 November 2017

\begin{abstract}
Objective: Front-of-package (FOP) marketing strategies of a wide variety of beverages were catalogued to examine the prevalence of each strategy prior to a sweeping Chilean restriction of child-directed marketing aimed at reducing obesity-related disease among Chile's youth.

Design: Photographs of 1005 beverage packages were quantitatively contentanalysed to code whether a variety of child-directed, health-oriented and other marketing strategies (e.g. sales promotions) were present on each product's FOP. Strategies were then analysed based on beverages' product category, total sugar, energy and tax status (beverages with added sugars are taxed at different rates). Setting: Photographs were taken in six urban supermarkets in Santiago, Chile, representing five different supermarket chains.

Results: Beverages using child-directed characters or nature/fruit references were higher in total sugar and beverages with child-directed characters or childhood/ family references were higher in energy than beverages without these respective strategies. Of the beverages taxed at the highest rate (greatest amount of added sugars), 49\% used nutrition and health appeals and $80 \%$ used nature or fruit appeals. Plain waters and plain milks were less likely than other selected product categories to use health-oriented appeals or multiple FOP strategies in combination.

Conclusions: FOP marketing on beverages varied according to the nutritional quality of the product, with heavier use of health-oriented and child-directed strategies in less healthy products. Marketing activities warrant continued observation to evaluate how industry responds to new marketing restrictions as these restrictions are evaluated in the light of existing taxes and other regulatory efforts to improve diets and reduce obesity-related disease.
\end{abstract}

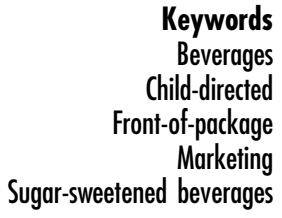

Beverages

Marketing

Sugar-sweetened beverages
Sugar-sweetened beverage (SSB) consumption has been increasing globally in recent decades ${ }^{(1)}$, as has SSB marketing $^{(2)}$, with about \$US 2 billion spent on SSB marketing worldwide in $2006^{(2)}$. These coexisting trends are alarming, as SSB consumption relates to overweight and obesity both directly through excess energy intake ${ }^{(3)}$ and indirectly through overall diet patterns $^{(4)}$ across ages $^{(5)}$ from pre-school ${ }^{(6)}$ to adolescence $^{(7)}$ and adulthood ${ }^{(8)}$, while advertising and frontof-package (FOP) marketing ${ }^{(9)}$ contribute to positive attitudes, preferences and consumption of these products ${ }^{(10-14)}$.

Chile leads the world in SSB sales at $787 \mathrm{~kJ}$ (188 kcal)/ capita per d based on 2014 sales data $^{(15)}$ and has among the highest overweight and obesity prevalence rates worldwide. About $11 \%$ of Chilean children $<6$ years of age are obese; $60 \%$ of people aged $>15$ years are overweight or obese ${ }^{(16-18)}$. Guided by $\mathrm{WHO}^{(19)}$ and Organisation for Economic Co-operation and Development ${ }^{(20)}$ recommendations, as well as other governments' efforts to reduce unhealthy food/beverage marketing ${ }^{(21)}$, the Chilean Government passed a series of regulations to improve the local food environment and reduce obesity-related disease in the population, especially in children. A prior $13 \%$ beverage tax (beyond the existing value-added tax) was raised in October 2014 to $18 \%$ for SSB with $>6.25 \mathrm{~g}$ sugars $/ 100 \mathrm{ml}$ and lowered to $10 \%$ for drinks with $\leq 6.25 \mathrm{~g}$ sugars/100 ml. Unflavoured waters, milks and milk-based 
beverages, and $100 \%$ fruit juices are tax-exempt ${ }^{(22)}$. Then, a regulation ${ }^{(23)}$ was implemented in July 2016 which requires FOP warning labels (black octagonal stop signs) to identify products high in saturated fat, total sugar, sodium and energy, and restricts child-directed ( $\leq 14$ years) marketing for those products, with plans for an additional regulation banning advertisements of unhealthy food/beverages across daytime television.

Chile's regulations represent the most comprehensive attempt by any country to restrict marketing for the purpose of reducing obesity-related disease. Yet, little is known about the FOP marketing used on beverage packaging, or whether those strategies differ by beverage type or nutritional content. According to extant literature on food marketing, unhealthy products (e.g. candies) are often marketed with child-directed strategies ${ }^{(10,21,24)}$, including cartoon and youth characters, references to school or childhood experiences, and appeals suggesting fun or play ${ }^{(24-27)}$. Thus, we expect that child-directed strategies will be more commonly used on unhealthy beverages (e.g. SSB) that are higher in sugars and energy than on the healthier beverages exemplifying national healthy diet promotion initiatives ${ }^{(23,28,29)}$, i.e. beverages such as the plain waters and milk recommended by Chilean and global nutritional guidelines ${ }^{(28,30-34)}$.

We also expect to find ample presence of healthoriented appeals in products contrary to dietary recommendations. Product packaging across food categories has also been shown to feature implicit and explicit health and nutrition claims, especially for products high in sodium, saturated fat or sugars, e.g. labelling a high-sugar product as low in $\mathrm{fat}^{(35,36)}$. Also problematic, products using multiple marketing strategies (i.e. child-directed and health-oriented strategies) are often lower in nutritional value than products that do not combine those strategies $^{(37)}$. We therefore anticipate a greater number of different marketing strategies observed on packages of unhealthy beverages, compared with plain waters and milk. However, the extant literature does not address what specific combinations of appeals will be most prevalent, based on the type of beverage.

The present study tests the following hypotheses using a comprehensive sample of beverage packages sold in Chilean supermarkets in 2015, one year after the new SSB tax and before the marketing regulation was implemented. FOP marketing strategies are evaluated according to beverage type, sugars and energy. Addressing these hypotheses provides a deeper understanding of the marketing of different beverage options, as well as a baseline for the longitudinal evaluation of the most comprehensive food labelling and marketing regulation to date.

H1. Use of child-directed FOP marketing strategies will be least common among plain waters and plain milks, compared with other beverage categories.
H2. Use of health-related FOP marketing strategies will be least common among plain waters and plain milks, compared with other beverage categories.

H3. Beverages that use child-directed FOP marketing strategies are more likely to be higher in total sugars, compared with beverages that do not use these strategies.

H4. Beverages that use health-related FOP marketing strategies are more likely to be higher in total sugars, compared with beverages that do not use these strategies.

H5. Beverages that use child-directed FOP marketing strategies are more likely to be higher in energy, compared with beverages that do not use these strategies.

H6. Beverages that use health-related FOP marketing strategies are more likely to be higher in energy, compared with beverages that do not use these strategies.

H7. Compared with plain waters and plain milks, other beverage categories will use a greater number of different FOP marketing strategies on their packaging.

In addition to these hypotheses, the following research question is addressed regarding the combined use of different marketing strategies on beverage packages:

RQ1. Which FOP marketing strategies most commonly appear together on the packaging of different beverage categories?

\section{Methods}

\section{Sample}

Photographs of beverage packages ( $n$ 1005) were obtained from a larger food and beverage sample collected from five different Chilean supermarket chains between February and April 2015 (plain waters and milks were gathered during February-March 2016) as part of the food environment monitoring activities of the International Network for Food and Obesity/Non Communicable Diseases Research, Monitoring and Action Support (INFORMAS) $^{(4)}$. Six supermarkets (one each from four chains, two from one chain) were visited, all of which were located in a high-income Santiago neighbourhood. Market selection was based on an agreement between the Association for Supermarkets and the University of Chile's Nutrition and Food Technology Institute ${ }^{(38)}$.

Beverage categories encompassed the scope of the Chilean food labelling and marketing regulation (alcohol is excluded). Over two days of data collection, fieldworkers photographed as many sub-categories of products as possible in each market, avoiding duplication. Photographs were continually logged so that fieldworkers would know which packages had already been captured in another market and therefore did not need to be 
photographed again. Photographs of the largest package size were taken when more than one package size of a given product was available, provided the same marketing strategies were used on these sizes. If different marketing strategies were deployed in the different package sizes, photographs were taken of each size.

Packages were grouped according to nutrients and product type by a team of trained Chilean and American nutritionists. Groups included: (i) 'plain waters' (plain and sparkling unflavoured water); (ii) 'sports drinks and flavoured waters' (flavoured water with and without sugar, liquid tea, isotonic sports drinks); (iii) 'soft drinks with sugar'; (iv) 'soft drinks without sugar'; (v) '100\% fruit juice' (including 100\% fruit pulp for reconstituting into $100 \%$ fruit juice); (vi) 'fruit-flavoured drinks' (sugary and diet fruitflavoured drinks, nectars, frozen and non-frozen pulps, and concentrated juices); (vii) 'powder drinks' (sugary and diet/ light); (viii) 'plain milks' (liquid and powdered skimmed, reduced-fat and whole unflavoured milk); and (ix) 'milkbased beverages' (liquid and powdered drinks containing milk, including skimmed, reduced-fat and whole flavoured milks and liquid yoghurt).

\section{Coding of marketing strategies}

FOP marketing appeals, promotions and incentives on the sampled packages were quantitatively assessed using categories of text and images that a team of trained mass communication scholars, including one Chilean, derived from previous marketing studies ${ }^{(9-11,14,24,27,35,39-53)}$. Chile's food labelling and marketing regulation ${ }^{(23)}$ was used as a reference. Two coders assessed the presence or absence of marketing appeals, which were combined into seven overarching categories of marketing strategies based on their thematic similarity (Table 1 shows specific appeals within each category): (i) nutrition and health claims; (ii) nature and fruit depictions; (iii) emotion and fun appeals; (iv) child-directed characters; (v) childhood and family situations; (vi) sports references and physical activity portrayals; and (vii) product-oriented appeals.

Presence/absence assessments were made irrespective of the quantity of specific iterations of any one strategy. For example, within the child-directed characters category, the sub-category of personified animal was coded as present regardless of whether there were one or more personified animals on the FOP. Then, the overall strategy of use of characters was assessed as present if at least one sub-category was coded as present. Presence of gifts (e.g. stickers, toys), games and contests was also initially coded, but their frequency of occurrence was minimal. Therefore, gifts, games and toys as marketing strategies were excluded from the reported analyses. The codebook is available as online supplementary material.

\section{Coding reliability}

A random selection of $20 \%$ of the sample ( $n$ 202) was analysed by each of the two trained coders to assess inter-rater reliability using ReCal software ${ }^{(54)}$ prior to splitting the remaining $80 \%$ of the sample between the coders ${ }^{(55)}$. Coders achieved between 92.87 and $99.67 \%$ agreement on each marketing strategy (e.g. nutritional and health appeals) and between 88.12 and $100 \%$ agreement on the individual codes comprising the strategy (Scott's $\pi=0.81,96.99 \%$ agreement across all codes).

\section{Product categorization}

Product names, brands, product descriptions and ingredients were used to place each beverage into one of the nine categories noted above (plain waters, sports/ flavoured waters, soft drinks with or without sugar, $100 \%$ fruit juice, fruit-flavoured drinks, powders, plain milks, or milk-based beverages). Total sugars $(\mathrm{g} / 100 \mathrm{ml})$ and energy $(\mathrm{kcal} / 100 \mathrm{ml} ; 1 \mathrm{kcal}=4.184 \mathrm{~kJ})$ were also recorded for each beverage using the nutrition facts panel data provided on the packages. Although mandatory in Chile to declare sugar content, thirty-two packages did not provide sugar information and so sugars were imputed by a trained dietitian based on nutrition information on packages sharing the same product sub-category, brand, tax status and ingredients as the package in question. For powders and concentrated formats, sugars and energy were computed based on the reconstituted product.

Tax status was also considered, as it reflects total sugars, yet notably excludes $100 \%$ juice and milk-based beverages. Based on Chilean law, the following products were assigned an $18 \%$ tax rate if they contained $>6.25 \mathrm{~g}$ total sugars/ $100 \mathrm{ml}$ and a $10 \%$ tax rate if they contained $\leq 6.25 \mathrm{~g}$ total sugars $/ 100 \mathrm{ml}$ : natural or artificially flavoured non-alcoholic beverages; energy or hypertonic drinks; syrups and any product that uses syrups to make a beverage; and mineral or thermal waters with added colour, flavour or sweeteners. Plain waters, milks and milk-based beverages, and $100 \%$ fruit juice were assigned a $0 \%$ beverage tax rate.

\section{Statistical analysis}

For each FOP marketing strategy (e.g. emotion and fun appeals, use of child-directed characters), a $\chi^{2}$ analysis was used to evaluate whether the prevalence of that strategy differed according to beverage taxation status (untaxed, $10 \%, 18 \%)$. Post hoc Fisher's exact probability $z$ tests provided pairwise comparisons between tax rates within any strategy that significantly differed in its prevalence based on tax status. The same procedure was used to test $\mathrm{H} 1$ and $\mathrm{H} 2$ by detecting differences in the prevalence of each marketing strategy across product category (e.g. soft drinks with sugar), with post hoc pairwise comparisons performed between each of the taxed product categories and the tax-exempt plain waters, plain milks and $100 \%$ fruit juice categories.

Descriptive and inferential statistics ( $t$ tests) were used to compare the average amount of sugars ( $\mathrm{H} 3$ and $\mathrm{H} 4)$ and energy ( $\mathrm{H} 5$ and $\mathrm{H} 6$ ) in products using ( $v$. not using) each marketing strategy. An adjusted $t$ test was used in the 
few cases when variances between groups were unequal (noted in the relevant tables). $\mathrm{H} 7$ was tested with an ANOVA (and post hoc pairwise mean comparisons) to compare the average number of different types of marketing strategies used across the different product categories (range $=0$ to 7 types of strategies). Frequencies were used to address RQ1, identifying the marketing strategies most likely to be used in tandem, depending on product category. All analyses were conducted with the statistical software package IBM SPSS Statistics version 24.

\section{Results}

According to $\chi^{2}$ tests of independence, the prevalence of use of six of the seven overarching marketing strategies on the front of beverage packages varied according to the beverages' taxation status, $\chi^{2}(2)$ ranging from 6.80 for product appeals to 189.32 for nutrition/health strategies, $P<0.05$. The one exception to this finding was that emotion and fun appeals were independent of taxation status, $\chi^{2}(2)=4 \cdot 10$,
$P=0 \cdot 13$. The proportions of products using these appeals according to product category and taxation status are shown in Table 1 . Beverages taxed at $10 \%$ were more likely to feature nutrition/health appeals and, to a much lesser extent, sports/physical activity references (93 and $17 \%$ of packages, respectively) than either untaxed products ( $80 \% ; 10 \%)$ or products with the $18 \%$ tax (49\%; $8 \%$ ). Also, significantly more of the untaxed products used nutrition/health appeals, compared with products at the $18 \%$ tax rate. Products taxed with either a $10 \%$ tax or a $18 \%$ tax were more likely to use nature/fruit depictions (80 and $82 \%$ of packages, respectively), compared with untaxed products (59\%).

Likely driven by the marketing strategies of milks and milk-based beverages, a greater number of untaxed products featured child-directed characters (19\%) and childhood and family references (5\%), compared with character use or child/family references among the $10 \%$ taxed or $18 \%$ taxed products (Table 1). Recall that milks and milk-based beverages are not taxed in Chile.

Mean energy and amount of total sugars for each FOP marketing strategy are shown in Tables 2 and 3,

Table 1 Results of $x^{2}$ tests. Proportion of products using at least one occurrence of a front-of-package marketing strategy and specific strategy tactic, based on product taxation status. Data from photographs of beverage packages taken in six urban supermarkets, representing five different supermarket chains, Santiago, Chile, 2015

\begin{tabular}{|c|c|c|c|c|c|c|c|c|}
\hline \multirow[b]{2}{*}{ Marketing strategy } & \multicolumn{2}{|c|}{$\begin{array}{l}\text { All beverages } \\
\quad(N 1005)\end{array}$} & \multicolumn{2}{|c|}{$\begin{array}{l}\text { Untaxed } \\
(N 313)\end{array}$} & \multicolumn{2}{|c|}{$\begin{array}{l}10 \% \text { tax } \\
(N 424)\end{array}$} & \multicolumn{2}{|c|}{$\begin{array}{l}18 \% \operatorname{tax} \\
(N 268)\end{array}$} \\
\hline & $n$ & $\%$ & $n$ & $\%$ & $n$ & $\%$ & $n$ & $\%$ \\
\hline Nutrition and health & 777 & 77 & 252 & $81^{\mathrm{a}}$ & 395 & $93^{b}$ & 130 & $49^{c}$ \\
\hline High-in/added/wholesome claims & 619 & 62 & 161 & 51 & 143 & 34 & 64 & 24 \\
\hline Low-in claims (e.g. low fat) & 574 & 57 & 205 & 66 & 349 & 82 & 20 & 7 \\
\hline Guideline Daily Amounts present & 217 & 22 & 45 & 14 & 113 & 27 & 59 & 22 \\
\hline Health benefits claims & 73 & 7 & 37 & 12 & 24 & 6 & 12 & 5 \\
\hline Claims of physical well-being & 67 & 7 & 5 & 2 & 47 & 11 & 15 & 6 \\
\hline Nature and fruit & 742 & 74 & 183 & $59^{\mathrm{a}}$ & 339 & $80^{\mathrm{b}}$ & 220 & $82^{b}$ \\
\hline Fruit depicted (e.g. apple image) & 654 & 65 & 116 & 37 & 330 & 78 & 208 & 77 \\
\hline Nature depicted (e.g. tree image) & 619 & 62 & 157 & 50 & 262 & 62 & 200 & 74 \\
\hline Emotion and fun & 115 & 11 & 45 & $14^{\mathrm{a}}$ & 41 & $10^{\mathrm{b}}$ & 29 & $11^{\mathrm{a}, \mathrm{b}}$ \\
\hline Mood alteration (e.g. be happy) & 58 & 6 & 12 & 4 & 27 & 6 & 19 & 7 \\
\hline Popular or fun words (e.g. cool) & 51 & 5 & 11 & 4 & 26 & 6 & 14 & 5 \\
\hline Magic/adventure/fantasy reference & 28 & 3 & 22 & 7 & 2 & $>1$ & 4 & 2 \\
\hline Child-directed characters & 86 & 9 & 60 & $19^{a}$ & 16 & $4^{b}$ & 10 & $4^{b}$ \\
\hline Personified object & 23 & 2 & 16 & 5 & 3 & 1 & 4 & 2 \\
\hline Personified product or ingredient & 18 & 2 & 3 & 1 & 12 & 3 & 3 & 1 \\
\hline Personified animal & 17 & 2 & 14 & 5 & 0 & 0 & 3 & 1 \\
\hline Child/youth character & 18 & 2 & 17 & 5 & 1 & $>1$ & 0 & 0 \\
\hline Fantastical adult (e.g. superhero) & 11 & 1 & 11 & 4 & 0 & 0 & 0 & 0 \\
\hline Childhood and family & 24 & 2 & 17 & $5^{a}$ & 5 & $1^{\mathrm{b}}$ & 2 & $>1^{\mathrm{b}}$ \\
\hline Family referenced or depicted & 15 & 2 & 10 & 3 & 3 & $>1$ & 2 & $>1$ \\
\hline Children referenced (e.g. for kids) & 8 & $>1$ & 5 & 2 & 3 & $>1$ & 0 & 0 \\
\hline School referenced or depicted & 3 & $>1$ & 3 & 1 & 0 & 0 & 0 & 0 \\
\hline Sports and physical activity & 122 & 12 & 31 & $10^{\mathrm{a}}$ & 70 & $17^{\mathrm{b}}$ & 21 & $8^{\mathrm{a}}$ \\
\hline Character being physically active & 84 & 8 & 27 & 10 & 42 & 10 & 12 & 5 \\
\hline Sports referenced or depicted & 53 & 5 & 4 & 1 & 38 & 9 & 11 & 4 \\
\hline Product-oriented & 158 & 16 & 37 & $12^{\mathrm{a}}$ & 80 & $19^{\mathrm{b}}$ & 41 & $15^{a, b}$ \\
\hline Claims of being new or improved & 57 & 6 & 13 & 4 & 30 & 7 & 14 & 5 \\
\hline Comparisons (e.g. better than...) & 55 & 6 & 18 & 6 & 27 & 6 & 10 & 4 \\
\hline Affordability, price promotions & 21 & 2 & 4 & 1 & 7 & 2 & 10 & 4 \\
\hline Invitations to try (e.g. try it) & 18 & 2 & 2 & $>1$ & 9 & 2 & 7 & 3 \\
\hline Unconventional (e.g. neon colour) & 11 & 1 & 1 & $>1$ & 10 & 2 & 0 & 0 \\
\hline
\end{tabular}

Untaxed products include plain and sparkling water, milk and milk-based beverages, and $100 \%$ fruit juices.

a,b,c Proportions within a row with unlike superscript letters were significantly different at $P<0.05$ according to post hoc Fisher $z$ tests. Comparisons made within overarching marketing strategies only. Proportions for all beverages are excluded from these comparisons. 
Table 2 Results of independent-sample $t$ tests. Average amount of energy in $\mathrm{kcal} / 100 \mathrm{ml}(1 \mathrm{kcal}=4.184 \mathrm{~kJ})$ in beverage products based on presence/absence of each front-of-package (FOP) marketing strategy. Data from photographs of beverage packages taken in six urban supermarkets, representing five different supermarket chains, Santiago, Chile, 2015

\begin{tabular}{|c|c|c|c|c|c|c|c|}
\hline \multirow[b]{2}{*}{ Marketing strategy } & \multicolumn{3}{|c|}{ Strategy not on FOP } & \multicolumn{3}{|c|}{ Strategy used on FOP } & \multirow[b]{2}{*}{$\operatorname{Mean}_{2}-$ Mean $_{1}$} \\
\hline & Mean $_{1}$ & SD & $n$ & Mean $_{2}$ & SD & $n$ & \\
\hline Nutrition and health $\dagger$ & 38.56 & $17 \cdot 74$ & 228 & $26 \cdot 50$ & 22.59 & 777 & $-12 \cdot 06^{*}$ \\
\hline Nature and fruit & 30.40 & 23.69 & 263 & 28.83 & 21.59 & 742 & -1.57 \\
\hline Emotion and fun & $29 \cdot 39$ & $22 \cdot 24$ & 890 & $28 \cdot 10$ & 21.64 & 115 & -1.29 \\
\hline Child-directed characters $\dagger$ & 28.02 & 21.90 & 919 & $42 \cdot 26$ & $20 \cdot 87$ & 86 & $14 \cdot 24^{*}$ \\
\hline Childhood and family & 28.99 & $22 \cdot 04$ & 981 & 39.62 & 24.98 & 24 & $10 \cdot 63^{*}$ \\
\hline Sports and physical activity & 29.90 & $22 \cdot 10$ & 883 & 24.50 & 22.09 & 122 & $-5 \cdot 40^{\star}$ \\
\hline Product-oriented & 29.75 & $22 \cdot 27$ & 847 & $26 \cdot 51$ & 21.45 & 158 & $-3 \cdot 24$ \\
\hline
\end{tabular}

${ }^{\star} P<0.05$

†Adjusted $t$ test due to statistically significant Levene's test for equality of variances.

Table 3 Results of independent-sample $t$ tests. Average amount of sugars in $\mathrm{g} / 100 \mathrm{ml}$ in beverage products based on presence/absence of each front-of-package (FOP) marketing strategy. Data from photographs of beverage packages taken in six urban supermarkets, representing five different supermarket chains, Santiago, Chile, 2015

\begin{tabular}{|c|c|c|c|c|c|c|c|}
\hline \multirow[b]{2}{*}{ Marketing strategy } & \multicolumn{3}{|c|}{ Strategy not on FOP } & \multicolumn{3}{|c|}{ Strategy used on FOP } & \multirow[b]{2}{*}{$\operatorname{Mean}_{2}-$ Mean $_{1}$} \\
\hline & Mean $_{1}$ & SD & $n$ & Mean $_{2}$ & SD & $n$ & \\
\hline Nutrition and health & $8 \cdot 19$ & 4.07 & 228 & 4.62 & $4 \cdot 15$ & 777 & $-3.57^{\star}$ \\
\hline Nature and fruit & 4.90 & $4 \cdot 11$ & 263 & $5 \cdot 61$ & 4.48 & 742 & $0.71^{*}$ \\
\hline Emotion and fun & 5.44 & 4.40 & 890 & $5 \cdot 33$ & 4.37 & 115 & -0.11 \\
\hline Child-directed characters $†$ & $5 \cdot 35$ & 4.49 & 919 & $6 \cdot 30$ & $3 \cdot 15$ & 86 & $0.95^{*}$ \\
\hline Childhood and family & 5.43 & 4.41 & 981 & 5.46 & 3.78 & 24 & 0.03 \\
\hline Sports and physical activity & 5.55 & 4.42 & 883 & 4.57 & $4 \cdot 12$ & 122 & $-0.98^{*}$ \\
\hline Product-oriented & 5.46 & 4.36 & 847 & $5 \cdot 27$ & 4.60 & 158 & $-0 \cdot 19$ \\
\hline
\end{tabular}

${ }^{*} P<0.05$.

†Adjusted $t$ test due to statistically significant Levene's test for equality of variances.

respectively, with results of the $t$ tests comparing means based on use ( $v$. non-use) of each strategy as follows. Products that deployed a nutrition and health strategy were lower on average in both total energy (kcal) and sugars $(\mathrm{g})$ per $100 \mathrm{ml}$, compared with products that did not use a nutrition/health strategy (energy: $t(463 \cdot 86)=-8.45$, $P<0.05$; sugars: $t(1003)=-11.47, \quad P<0.05)$. A similar pattern was seen for sports and physical activity appeals, in that use of this strategy was indicative of products with lower amounts of energy and sugars rather than higher amounts of energy and sugars (energy: $t(1003)=-2.53$, $P<0.05$; sugars: $t(1003)=-2.31, P<0.05)$.

Conversely, products that used FOP child-directed characters were significantly higher in both energy and sugars, compared with products that did not use them (energy: $t(103.32)=6 \cdot 02, P<0.05$; sugars: $t(119 \cdot 99)=2 \cdot 56, P<0.05)$. Also, packages featuring a childhood or family reference had more energy per $100 \mathrm{ml}$, on average, than packages without this reference $(t(1003)=2.33, \quad P<0.05)$, and packages with a nature or fruit representation tended to have more sugars than packages that did not use this type of strategy $(t(497.44)=2.36, P<0.05)$. In the light of innate differences in the composition of milks (i.e. fats, lactose) compared with other beverages, the above analyses were repeated within milks and milk-based beverages combined, as well as within the remaining sample minus milks and milk-based beverages (data not shown). Findings noted above were, for the most part, robust across these subgroups. Qualifying the differences in FOP use of childhood/ family references and child-directed characters, statistical significance was found only within milks and milk-based beverages but not within the remaining sample.

Detailed in Table 4, the prevalence of each type of FOP marketing strategy (e.g. nutrition and health, emotion and fun) depended on the type of product being marketed; $\chi^{2}$ results comparing the prevalence of each strategy across the product categories ranged from $\chi^{2}(8)=12.92$ (emotion/fun) to 375.45 (nature/fruit), $P<0 \cdot 05$. Nutrition/health strategies were on nearly all powder drinks and on all soft drinks without sugar, whereas these strategies appeared on significantly fewer plain waters, plain milks or $100 \%$ fruit juice packages (Table 4). Nutrition/health strategies were also more likely to exist on milk-based beverage packages (89\%), when compared with plain waters (63\%) or $100 \%$ fruit juice (56\%). More sports drinks/flavoured waters also contained nutrition/health appeals, compared with plain waters and $100 \%$ fruit juice. Worthy of note, a similar percentage of soft drinks with sugar (48\%) employed nutrition/health strategies as plain waters (63\%) and $100 \%$ fruit juice (56\%). Fewer nutrition/health 
Table 4 Results of $\chi^{2}$ tests. Percentage of products in a given product category using at least one occurrence of each front-of-package marketing strategy. Data from photographs of beverage packages taken in six urban supermarkets, representing five different supermarket chains, Santiago, Chile, 2015

\begin{tabular}{|c|c|c|c|c|c|c|c|c|c|}
\hline \multirow[b]{2}{*}{$\begin{array}{l}\text { Marketing } \\
\text { strategy }\end{array}$} & \multicolumn{9}{|c|}{ Percentage of products per product category } \\
\hline & $\begin{array}{l}\text { Plain } \\
\text { waters } \\
(N 48)\end{array}$ & $\begin{array}{l}\text { Plain } \\
\text { milks } \\
(N 84)\end{array}$ & $\begin{array}{l}100 \% \\
\text { fruit juice } \\
(N 39)\end{array}$ & $\begin{array}{c}\text { Sports/ flavoured } \\
\text { waters } \\
(N 105)\end{array}$ & $\begin{array}{l}\text { Fruit-flavoured } \\
\text { drinks } \\
(N 296)\end{array}$ & $\begin{array}{l}\text { Powder } \\
\text { drinks } \\
(N 171)\end{array}$ & $\begin{array}{l}\text { Soft drinks } \\
\text { with sugar } \\
(N 60)\end{array}$ & $\begin{array}{l}\text { Soft drinks, } \\
\text { no sugar } \\
(N 60)\end{array}$ & $\begin{array}{c}\text { Milk-based } \\
\text { beverages } \\
(N 142)\end{array}$ \\
\hline $\begin{array}{l}\text { Nutrition and } \\
\text { health }\end{array}$ & $63^{\mathrm{B}}$ & $87^{A, C}$ & $56^{\mathrm{B}}$ & $80^{\mathrm{A}, \mathrm{C}}$ & $62^{\mathrm{B}}$ & $99^{\mathrm{A}, \mathrm{B}, \mathrm{C}}$ & $48^{B}$ & $100^{A, B, C}$ & $89^{A, C}$ \\
\hline Nature and fruit & $56^{\mathrm{B}, \mathrm{C}}$ & $25^{\mathrm{A}, \mathrm{C}}$ & $92^{\mathrm{A}, \mathrm{B}}$ & $56^{\mathrm{B}, \mathrm{C}}$ & $98^{\mathrm{A}, \mathrm{B}, \mathrm{C}}$ & $98^{\mathrm{A}, \mathrm{B}, \mathrm{C}}$ & $38^{\mathrm{C}}$ & $30^{A, C}$ & $70^{\mathrm{A}, \mathrm{B}, \mathrm{C}}$ \\
\hline Emotion and fun & $23^{\mathrm{B}}$ & $8^{\mathrm{A}}$ & 21 & 11 & $10^{\mathrm{A}, \mathrm{C}}$ & $9^{A, C}$ & 13 & 12 & 13 \\
\hline $\begin{array}{l}\text { Child-directed } \\
\text { characters }\end{array}$ & 6 & $12^{\mathrm{C}}$ & $0^{\mathrm{B}}$ & $1^{\mathrm{B}}$ & 6 & $4^{\mathrm{B}}$ & $2^{B}$ & $0^{\mathrm{B}}$ & $33^{A, B, C}$ \\
\hline $\begin{array}{l}\text { Childhood and } \\
\text { family }\end{array}$ & 6 & $10^{\mathrm{C}}$ & $0^{\mathrm{B}}$ & $0^{\mathrm{A}, \mathrm{B}}$ & $2^{\mathrm{B}}$ & $0^{\mathrm{A}, \mathrm{B}}$ & $0^{\mathrm{B}}$ & $0^{\mathrm{B}}$ & 4 \\
\hline $\begin{array}{l}\text { Sports and } \\
\text { physical } \\
\text { activity }\end{array}$ & 2 & 6 & 0 & $50^{A, B, C}$ & 6 & $11^{\mathrm{C}}$ & 2 & 0 & $18^{\mathrm{A}, \mathrm{B}, \mathrm{C}}$ \\
\hline Product-oriented & 6 & 11 & 10 & 15 & 11 & $29^{\mathrm{A}, \mathrm{B}, \mathrm{C}}$ & $20^{\mathrm{A}}$ & 18 & 15 \\
\hline
\end{tabular}

${ }_{\mathrm{A}, \mathrm{B}, \mathrm{C}}$ Percentages within a row with superscript letters were significantly different from that for ${ }^{\mathrm{A}}$ plain waters, ${ }^{\mathrm{B}}$ plain milks and/or ${ }^{\mathrm{C}} 100 \%$ fruit juice at $P<0.05$ based on post hoc Fisher's exact probability tests ( $z$ tests).

appeals existed among soft drinks with sugars than among plain milks (87\%).

Depictions of nature or fruit were widely used on soft drinks without sugar, powder drinks, fruit-flavoured drinks, milk-based beverages, $100 \%$ juice, and on nearly half of all soft drinks with sugar. These depictions were rare among plain milks. Powders, fruit-flavoured drinks and $100 \%$ juices were also more likely to use a nature or fruit appeal, compared with plain waters. Sports/physical activity references were on half of the sports drinks/ flavoured waters and one-fifth of the milk-based beverages, but largely absent for plain waters, plain milks and $100 \%$ fruit juice.

The use of child-directed characters was seen on onethird of milk-based beverages, yet rarely occurred on plain waters, plain milks or $100 \%$ fruit juice packages, although plain milks did feature FOP characters more often than either plain waters or $100 \%$ fruit juices. Emotion/fun appeals were more widely used on plain waters, compared with many other product categories, including plain milks (Table 4). Product-based appeals appeared on onethird of powder drinks, whereas they were rarely used on plain waters, plain milks or $100 \%$ fruit juice packages. Soft drinks with sugar were more likely to feature productbased appeals than plain waters.

Overall, relatively few plain waters, plain milks and $100 \%$ fruit juice packages employed the examined marketing strategies, compared with the other product categories. The only exception to this statement concerns the rarely used childhood/family appeals; these appeals were employed on $6 \%$ of plain waters and $10 \%$ of plain milks but were essentially absent for sports/flavoured waters, fruit-flavoured drinks and powder drinks (Table 4).

Shown in Table 5, nutrition/health and nature/fruit appeals were most commonly used together on packages for all but one product category; $56 \%$ of the overall sample contained this pairing. Sports/flavoured waters were the exception, where half $(50 \%)$ of those packages featured the combination of nutrition/health and sports/ physical activity. With few exceptions, products that used multiple strategies featured nutrition and health appeals as one of the strategies alongside a variety of other tactics, including product-oriented appeals (e.g. powders, soft drinks), emotion and fun appeals (e.g. soft drinks, plain waters, $100 \%$ fruit juice), and use of child-directed characters (e.g. plain milks and milk-based beverages).

The average number of different marketing strategies used on FOP (mean (SD)) varied according to the type of product, $F(8,996)=22 \cdot 49, P<0 \cdot 01$. According to pairwise post hoc comparisons (Table 6), powder drinks (2.51 $(0 \cdot 65))$ and milk-based beverages $(2 \cdot 46(1 \cdot 10))$ used more than two types of marketing strategies on average, which is a significantly greater number of strategies compared with the number of strategies used by other product categories, at $P<0.05$. Soft drinks with sugar $(1.22(0.94))$ and without sugar $(1.60(0.64))$, plain waters $(1.63(0.89))$ and plain milks (1.61 (1.01)) used the fewest number of strategies on their FOP on average, significantly fewer than the above categories, but also fewer than sports/flavoured waters $(2.13(0.82))$ and fruit-flavoured drinks (1.95 (0.81)), based on pairwise comparisons evaluated at $P<0 \cdot 05$. The number of FOP strategies used by $100 \%$ fruit juices $(1.79(0.73))$ was similar to that of fruit-flavoured drinks.

\section{Discussion}

FOP marketing is a key component of integrated marketing campaigns that include television and Internet advertising ${ }^{(56,57)}$, and a focus of Chile's regulatory efforts to decrease obesity rates. The present study revealed a 
Table 5 Results of cross-tabulations between front-of-package marketing strategies. Top three co-occurring marketing strategies for the full sample and for each product category. Data from photographs of beverage packages taken in six urban supermarkets, representing five different supermarket chains, Santiago, Chile, 2015

\begin{tabular}{|c|c|c|c|}
\hline Product category & Most commonly co-occurring marketing strategies & $n$ & $\%$ \\
\hline \multirow[t]{3}{*}{ All beverages ( $N$ 1005) } & Nutrition/health \& Nature/fruit & 558 & 56 \\
\hline & Nutrition/health \& Product-oriented & 140 & 14 \\
\hline & Nature/fruit \& Product-oriented & 120 & 12 \\
\hline \multirow{3}{*}{ Plain and sparkling water $(N 48)$} & Nutrition/health \& Nature/fruit & 14 & 29 \\
\hline & Nutrition/health \& Emotion/fun & 9 & 19 \\
\hline & Nature/fruit \& Emotion/fun & 5 & 10 \\
\hline \multirow[t]{3}{*}{ Sports drinks and flavoured waters ( $N 105)$} & Nutrition/health \& Sports/physical activity & 51 & 50 \\
\hline & Nutrition/health \& Nature/fruit & 38 & 37 \\
\hline & Nature/fruit \& Sports/physical activity & 27 & 26 \\
\hline \multirow[t]{3}{*}{ Soft drinks with sugar $(N 60)$} & Nutrition/health \& Nature/fruit & 19 & 24 \\
\hline & Nutrition/health \& Product-oriented & 9 & 11 \\
\hline & Nutrition/health \& Emotion/fun & 6 & 8 \\
\hline \multirow[t]{3}{*}{ Soft drinks, no sugar ( $N 60)$} & Nutrition/health \& Nature/fruit & 20 & 34 \\
\hline & Nutrition/health \& Product-oriented & 9 & 16 \\
\hline & Nutrition/health \& Emotion/fun & 7 & 13 \\
\hline \multirow{3}{*}{$100 \%$ fruit juice ( $N 39)$} & Nutrition/health \& Nature/fruit & 22 & 56 \\
\hline & Nature/fruit \& Emotion/fun & 7 & 18 \\
\hline & Nature/fruit \& Product-oriented & 4 & 10 \\
\hline \multirow[t]{3}{*}{ Fruit-flavoured drinks ( $N 296)$} & Nutrition/health \& Nature/fruit & 179 & 60 \\
\hline & Nature/fruit \& Product-oriented & 31 & 11 \\
\hline & Nature/fruit \& Emotion/fun & 28 & 10 \\
\hline \multirow[t]{3}{*}{ Powder drinks ( $N$ 171) } & Nutrition/health \& Nature/fruit & 167 & 98 \\
\hline & Nature/fruit \& Product-oriented & 50 & 29 \\
\hline & Nutrition/health \& Product-oriented & 49 & 29 \\
\hline \multirow[t]{4}{*}{ Plain milks ( $N 84)$} & Nutrition/health \& Nature/fruit & 19 & 23 \\
\hline & Nutrition/health \& Child-directed character & 10 & 12 \\
\hline & Nutrition/health \& Childhood/family & 8 & 10 \\
\hline & Nutrition/health Product-oriented & 8 & 10 \\
\hline \multirow{3}{*}{ Milk-based beverages $(N$ 142) } & Nutrition/health \& Nature/fruit & 90 & 63 \\
\hline & Nutrition/health \& Child-directed character & 45 & 32 \\
\hline & Nutrition/health \& Sports/physical activity & 24 & 17 \\
\hline
\end{tabular}

Table 6 Results of ANOVA. Comparison of the average number of different marketing strategies used on the front of packages (FOP), based on product category. Data from photographs of beverage packages taken in six urban supermarkets, representing five different supermarket chains, Santiago, Chile, 2015

\begin{tabular}{llcr}
\hline & \multicolumn{3}{c}{$\begin{array}{c}\text { Number of FOP strategies } \\
\text { used }\end{array}$} \\
\cline { 2 - 4 } Product category & Mean & SD & \multicolumn{1}{c}{$N$} \\
\hline All beverages & 2.02 & 0.93 & 1005 \\
Plain and sparkling water & $1.63^{\mathrm{c}}$ & 0.89 & 48 \\
Sports drinks and flavoured waters & $2.13^{\mathrm{d}}$ & 0.82 & 105 \\
Soft drinks with sugar & $1.22^{\mathrm{e}}$ & 0.94 & 60 \\
Soft drinks, no sugar & $1.60^{\mathrm{c}}$ & 0.64 & 60 \\
$100 \%$ fruit juice & $1.79^{\mathrm{b}, \mathrm{c}}$ & 0.73 & 39 \\
Fruit-flavoured drinks & $1.95^{\mathrm{b}, \mathrm{d}}$ & 0.81 & 296 \\
Powder drinks & $2.51^{\mathrm{a}}$ & 0.65 & 171 \\
Plain milks & $1.61^{\mathrm{c}}$ & 1.01 & 84 \\
Milk-based beverages & $2.46^{\mathrm{a}}$ & 1.10 & 142 \\
\hline
\end{tabular}

a,b,c,d Mean values with unlike superscript letters were significantly different at $P<0.05$ according to Fisher's Least Significant Difference post hoc pairwise comparison. Mean for all beverages is excluded from these pairwise comparisons.

number of differences in FOP marketing strategies on beverages available in Chilean supermarkets in 2015, according to the nutritional quality of the products. As hypothesized, beverages with child-directed characters had more sugars (H3) and energy (H5) than beverages without FOP characters, and beverages using childhood/ family references were also higher in energy than beverages without these references (H5). Partly supporting $\mathrm{H} 1$ and qualifying the above findings, flavoured milk-based beverages more often featured child-friendly characters than other beverages, including plain waters or plain milk. However, no such differences were found for use of childhood references or fun appeals; few packages in any category used these appeals. Thus, whereas the present study generally corroborates research finding that child-oriented marketing strategies, e.g. use of characters, are likely to be used with a variety of foods less healthy for children ${ }^{(24-27)}$, the primary finding for beverage packages centres on use of characters by flavoured milks, which suggests a strategic capitalization on children's information processing, as children are attracted to characters $^{(25)}$ or suggestions of fun ${ }^{(26,27,57,58)}$ in part because these appeals are easier to comprehend than nutritional information $^{(59,60)}$.

Yet, the present study also notes widespread use of health-oriented appeals. Almost half of the beverages taxed at the highest rate $(>6.25 \mathrm{~g}$ sugars $/ 100 \mathrm{ml})$ featured nutrition and health appeals and over $80 \%$ of these products featured nature and fruit references, suggesting a disconnect between policy and marketing messages. Addressing H2, powder drinks and soft drinks without 
sugar used nutrition and health claims more often that both plain waters and plain milks. Although $\mathrm{H} 4$ and $\mathrm{H} 6$ were not supported with a general difference in total sugar or energy between products (categories collapsed) using $v$. not using nutrition and health claims, beverages with nature or fruit references were shown to have significantly more sugars than beverages without these references. The frequency of nutrition, health, nature and fruit appeals found in the present study is consistent with other findings that packages across food categories often feature health-oriented marketing strategies, even if the product's overall nutrient profile is problematic (e.g. low in fat but high in sugar) ${ }^{(35,36)}$. These strategies are problematic because they can appeal to adults and youth alike ${ }^{(25,26,35,37,61-64)}$ and create a 'health halo' around the product, whereby consumers generalize the positive health attribute and overestimate the nutritional quality of the whole product ${ }^{(65-67)}$. Thus, a sugary product with a nature $^{(68)}$ or fruit image ${ }^{(69)}$ might capitalize on beliefs that real fruit, and real fruit sugar, is healthy ${ }^{(65,70,71)}$.

Potentially enhancing effects of health-oriented marketing strategies, the present study found that healthoriented appeals often co-occurred with other marketing strategies, such as use of characters, emotion/fun, sports and product appeals (addressing RQ1). For example, in support of $\mathrm{H} 7$, powder drinks, flavoured milk-based beverages and sports drinks/flavoured waters employed more FOP marketing strategies in tandem, compared with plain waters and plain milk. Soft drinks without sugar were similar to plain waters and plain milk in using few concurrent strategies. Using multiple strategies increases the information density of a package, which hinders consumers' ability to identify and process all of the information provided about a product ${ }^{(72)}$. Younger children are particularly vulnerable to multiple appeals ${ }^{(73)}$ because of limitations in literacy and capacity to process and retain more than one message at a time ${ }^{(60,74)}$. This understudied issue of information density might become particularly important when assessing the addition of the new mandatory 'high in' warning labels to product packages that also contain other marketing strategies, especially if those messages contain health-oriented appeals that seem to contradict the warnings. In any case, future research is needed to understand whether the use of health-oriented appeals alone and in combination with other appeals result in higher purchases and intake of unhealthy beverages, especially among children.

\section{Limitations}

The present study inherits sample limitations that prevent analyses of the prevalence of marketing strategies based on interactions between product categories and other nutritional qualifications, as there were not enough observations of each strategy in the sample to support this type of analysis. The five supermarket chains selected for sampling also reduces the generalizability of these findings to the markets that are part of the INFORMAS' food system monitoring project in urban Santiago. Moreover, photographs were based on the availability of products in those markets rather than beverage consumption patterns in the Chilean population. Although the sample of products obtained from these markets represents $76 \%$ of all beverage products purchased in Chile, according to Kantar Worldpanel's (2013-2015) nationally representative consumer panel, this sample might still exclude beverages and branding strategies (e.g. affordability appeals) that target supermarkets in demographically different neighbourhoods. Thus, even though many national brands exist across chains, regardless of the composition of the surrounding neighbourhood, future research beyond the current baseline study will include a wider sampling of supermarkets. Furthermore, the decision to photograph the largest packaging of a given product (e.g. an eightpack bundle), unless other marketing tactics were seen in smaller packages, introduces the possibility that different tactics on individual containers might have been obscured in the few cases when bulk packaging was not transparent or translucent.

The present study also focused on FOP marketing strategies, as FOP marketing is a key promotional medium that influences attitudes towards products and pointof-sale purchase decisions ${ }^{(13,57,75)}$. However, our coders noted that some products containing child-directed FOP strategies (e.g. characters) also featured strategies on the sides and/or backs of the products (data not shown). Thus, the decision to only examine FOP marketing might under-represent the amount of various marketing appeals used on the total surface of beverage packaging.

The present study also does not include FOP features related to visual design aspects, such as attractive colours or unconventional fonts. Such features have been argued as targeting children, e.g. an unconventional font suggesting fun ${ }^{(26,65)}$. However, these aspects are not included in the Chilean food marketing regulation ${ }^{(23)}$ and were ultimately excluded from the present study because of the difficulty in defining child-targeted ( $v$. other-targeted) visual design in the concrete terms needed for inclusion in a rigorous quantitative content analysis (or regulation). Still, visual design elements constitute part of an overall marketing strategy and exclusion of such aspects likely leads to underestimation of the prevalence of strategies that would appeal to children.

\section{Future directions}

The June 2016 Chilean regulations banning food marketing aimed at children ( $\leq 14$ years) are designed to eliminate the characters, fun appeals and childhood references seen in the present study and other research ${ }^{(10,21,24)}$ on the packaging of beverages high in total sugar, saturated fat, sodium or energy. First, given that SSB are a major contributor to excess intake of added sugars and energy, it is crucial that countries monitor, longitudinally, the marketing 
strategies on food and beverage packages and in other venues, e.g. corporate sponsorships, advertising or product placement $^{(73)}$, to evaluate how these strategies evolve in response to these regulations. The current study provides a baseline description of the types and prevalence of various marketing strategies, including child-directed strategies, that can be used to test new hypotheses about shifts in marketing efforts. Then, data on marketing shifts can be used in combination with both longitudinal survey data assessing changes in diet and longitudinal household-level purchase data to directly assess whether reducing these childdirected marketing strategies translates into a reduction of SSB consumption (or substitution to plain water), despite any marketing shifts.

Future research is also needed to determine whether including the 'high in' FOP warning labels implemented by the June 2016 regulation will provide consumers with an accurate impression of products' nutritional profiles, given these warnings will likely exist alongside health-oriented and other marketing appeals allowed by the regulation. The regulation currently forbids products with a 'high in' label from making claims about the identified excessive nutrient; thus, a 'high in saturated fat' product cannot claim to be low fat. There is also a regulation in process to ban certain specific nutrition claims in 'high in' products (other health appeals, e.g. use of the Guideline Daily Amount, are not covered). However, products with a 'high in sugar' warning, for example, can claim high calcium, wholesome ingredients or low fat content. Given the prevalence of health-oriented appeals found in the present study, we expect marketing efforts will shift to include even more of these appeals (e.g. more nature or fruit claims) as allowed by the regulation.

Perhaps the most important need for research is the assessment of how FOP marketing shifts couple with FOP warning labels and SSB taxation to impact children's intake of high-sugar beverages ${ }^{(76)}$. Based on the present study's findings, there is real concern about the information density on packages, especially if the information might suggest both healthy and unhealthy qualities of a product. At minimum, research is needed to examine the coexistence of tax and warning labels on products that currently use health-oriented appeals, as half of the beverages taxed for sugars content were found to feature such appeals. This line of research will also be useful for evaluating trends in consumption of flavoured milks and other milk-based beverages as potential substitutes of SSB in Chile, given both flavoured and plain milks are exempt from taxation and, as the present study found, flavoured milks used more characters and nature depictions than plain milk. Longitudinal data collection of products will be needed to note any reformulations of nutrients within beverages from this baseline collection, in addition to tracking changes in marketing strategies, to fully understand how the combination of marketing, warnings and taxation affects SSB purchases and intake in the Chilean youth population.

\section{Acknowledgements}

Acknowledgements: The authors thank Bloomberg Philanthropies, the International Development Research Centre, the University of North Carolina Institute for Global Health \& Infectious Diseases, and the Carolina Population Center for financial support. They also thank Natalia Rebolledo Fuentealba and Donna Miles for their exceptional assistance with categorizing beverages based on nutritional databases, Frances Dancy for administrative assistance, Dr Barry Popkin for his leadership and support, and the Carolina Population Center for general support. The authors also wish to thank the 'super chicas' who collected the photographs of food packages and the International Network for Food and Obesity/Non Communicable Diseases Research, Monitoring and Action Support (INFORMAS) group at the University of Chile's Institute of Nutrition and Food Technology for their continual support throughout the data collection. Financial support: Support comes primarily from Bloomberg Philanthropies, with additional support from International Development Research Centre (IDRC) grants 107731-002 (INFORMAS) and 108180-001 (INTA-UNC), CONICYT (FONDECYT \#1161436, FONDECYT Postdoctorado Proyecto \#3150183), the Carolina Population Center (P2C HD050924), and the University of North Carolina Institute for Global Health \& Infectious Diseases (Explorations in Global Health grant). Beyond financial support, funders had no role in the study design, data collection, analysis or interpretation. Conflict of interest: None of the authors have conflicts of interest of any type with respect to this manuscript. Authorship: F.M.S. led the content analysis, statistical analysis and writing. J.O.B. contributed to the content analysis. R.K. led the data collection. C.C. and M.R. supervised the data collection and contributed an initial codebook. L.S.T. contributed to the research design. F.R.D.C. supervised the study execution, analysis and writing. All authors contributed to manuscript edits. Ethics of human subject participation: No human subjects were involved in this study.

\section{Supplementary material}

To view supplementary material for this article, please visit https://doi.org/10.1017/S1368980017002671

\section{References}

1. Singh GM, Micha R, Khatibzadeh S et al. (2015) Global, regional, and national consumption of sugar-sweetened beverages, fruit juices, and milk: a systematic assessment of beverage intake in 187 countries. PLoS One 10, e0124845.

2. Federal Trade Commission (2012) A Review of Food Marketing to Children and Adolescents: Follow-Up Report. Washington, DC: Federal Trade Commission.

3. Hu FB (2013) Resolved: there is sufficient scientific evidence that decreasing sugar-sweetened beverage 
consumption will reduce the prevalence of obesity and obesity-related diseases. Obes Rev 14, 606-619.

4. Swinburn B, Sacks G, Vandevijvere S et al. (2013) INFORMAS (International Network for Food and Obesity/non-communicable diseases Research, Monitoring and Action Support): overview and key principles. Obes Rev 14, Suppl. 1, 1-12.

5. Malik VS, Schulze MB \& Hu FB (2006) Intake of sugarsweetened beverages and weight gain: a systematic review. Am J Clin Nutr 84, 274-288.

6. de Ruyter JC, Olthof MR, Seidell JC et al. (2012) A trial of sugar-free or sugar-sweetened beverages and body weight in children. $N$ Engl J Med 367, 1397-1406.

7. Forshee RA, Anderson PA \& Storey ML (2008) Sugar-sweetened beverages and body mass index in children and adolescents: a meta-analysis. Am J Clin Nutr 87, $1662-1671$.

8. Bray GA, Nielsen SJ \& Popkin BM (2004) Consumption of high-fructose corn syrup in beverages may play a role in the epidemic of obesity. Am J Clin Nutr 79, 537-543.

9. Cousté NL, Martos-Partal M \& Martínez-Ros E (2012) The power of a package. J Advert Res 52, 364-375.

10. Cairns G, Angus K, Hastings G et al. (2013) Systematic reviews of the evidence on the nature, extent and effects of food marketing to children. A retrospective summary. Appetite 62, 209-215.

11. Enax L, Weber B, Ahlers M et al. (2015) Food packaging cues influence taste perception and increase effort provision for a recommended snack product in children. Front Psychol 6, 882

12. Gutjar S, de Graaf C, Palascha A et al. (2014) Food choice: the battle between package, taste and consumption situation. Appetite 80, 109-113.

13. Harris JL, Pomeranz JL, Lobstein T et al. (2009) A crisis in the marketplace: how food marketing contributes to childhood obesity and what can be done. Annu Rev Public Health 30 , 211-225.

14. Skaczkowski G, Durkin S, Kashima Y et al. (2016) The effect of packaging, branding and labeling on the experience of unhealthy food and drink: a review. Appetite 99, 219-234.

15. Popkin BM \& Hawkes C (2016) Sweetening of the global diet, particularly beverages: patterns, trends, and policy responses. Lancet Diabetes Endocrinol 4, 174-186.

16. Ministerio de Salud - Departamento de Estadísticas e Información en Salud (Ministry of Health - Department of Statistics and Health Information) (2014) Indicadores Básicos de Salud: Chile 2014 (Basic Indicators of Health: Chile 2014). Santiago: MINSAL-DEIS; http://www.deis.cl/wpcontent/uploads/2015/04/IBS-2014.pdf (accessed October 2017).

17. Ministerio de Salud (Ministry of Health) (2010) Encuesta Nacional de Salud (ENS) 2009-2010 (National Health Survey (ENS) 2009-2010). Santiago: MINSAL-ENS.

18. Junta Nacional de Auxilio Escolar y Becas (National Scholarship and School Aid Board) (2013) Informe Mapa Nutricional 2013 (Nutritional Map Report 2013). Santiago: JUNAEB.

19. World Health Organization (2012) A Framework for Implementing the Set of Recommendations on the Marketing of Foods and Non-Alcoholic Beverages to Children. Geneva: WHO.

20. Sassi F (2010) Obesity and the Economics of Prevention: Fit not Fat. Paris: OECD Publishing.

21. Hawkes C \& Lobstein T (2011) Regulating the commercial promotion of food to children: a survey of actions worldwide. Int J Pediatr Obes 6, 83-94.

22. Ministerio de Salud (Chilean Ministry of Health) (2014) Ley N 20.780 reforma Tributaria que Modifica el Sistema de tributación de la renta e Introduce Diversos Ajustes en el Sistema Tributario (Tax reform that modifies the system of income taxation and introduces various adjustments in the tax system). https://www.leychile.cl/Navegar?idNorma= 1067194 (accessed October 2017).

23. Ministerio de Salud (Chilean Ministry of Health) (2015) Decreto N 13 que modifica decreto supremo N 977, de 1996, del Ministerio de Salud. Reglamento Sanitario de los Alimentos (Amendment to Ministry of Health supreme decree No. 977 of 1996. Food Health Regulations). http://www.wipo.int/edocs/lexdocs/laws/es/cl/cl074es.pdf (accessed October 2017).

24. Harris JL, LoDolce M, Dembek C et al. (2015) Sweet promises: candy advertising to children and implications for industry self-regulation. Appetite 95, 585-592.

25. Ares G, Arrua A, Antunez L et al. (2016) Influence of label design on children's perception of two snack foods: comparison of rating and choice-based conjoint analysis. Food Qual Prefer 53, 1-8.

26. Elliott C (2008) Marketing fun foods: a profile and analysis of supermarket food messages targeted at children. Can Public Policy 34, 259-273.

27. Roberto CA, Baik J, Harris JL et al. (2010) Influence of licensed characters on children's taste and snack preferences. Pediatrics 126, 88-93.

28. Ministerio de Salud (Chilean Ministry of Health) (2013) Estudio para Revisiòn y Actualizaciòn de las Guias Alimentarias para la Poblaciñón Chilena (Study to Review and Update the Dietary Guidelines for the Population of Chile). Santiago: MINSAL. http://web.minsal.cl/portal/url/ item/dde0bc471a56a001e040010165012224.pdf (accessed October 2017).

29. Olivares Cortés S, Zacarías Hasbún I, González González CG et al. (2015) Diseño y validación de la imagen para la difusión e implementación de las guías alimentarias para la población chilena (Design and validation of the plan for the diffusion and implementation of nutritional guidelines for the Chilean population). Nutr Hosp 32, 582-589.

30. Albala C, Ebbeling CB, Cifuentes M et al. (2008) Effects of replacing the habitual consumption of sugar-sweetened beverages with milk in Chilean children. Am J Clin Nutr 88, 605-611.

31. Hernandez-Cordero S, Barquera S, Rodriguez-Ramirez S et al. (2014) Substituting water for sugar-sweetened beverages reduces circulating triglycerides and the prevalence of metabolic syndrome in obese but not in overweight Mexican women in a randomized controlled trial. J Nutr 144, 1742-1752.

32. Zheng M, Rangan A, Allman-Farinelli M, Rohde JF et al. (2015) Replacing sugary drinks with milk is inversely associated with weight gain among young obesity-predisposed children. BrJ Nutr 114, 1448-1455.

33. Zheng M, Rangan A, Olsen NJ et al. (2015) Substituting sugar-sweetened beverages with water or milk is inversely associated with body fatness development from childhood to adolescence. Nutrition 31, 38-44.

34. World Health Organization (2002) Estrategia mundial sobre régimen alimentario, actividad física y salud (Global strategy on diet, physical activity, and health). http://www.who.int/ dietphysicalactivity/strategy/eb11344/strategy_spanish_web. pdf (accessed October 2017)

35. Colby SE, Johnson L, Scheett A et al. (2010) Nutrition marketing on food labels. J Nutr Educ Behav 42, 92-98.

36. Taillie LS, Ng SW, Xue Y et al. (2017) No fat, no sugar, no salt ... no problem? Prevalence of 'low-content' nutrient claims and their associations with the nutritional profile of food and beverage purchases in the United States. $J$ Acad Nutr Diet 117, 1366-1374.

37. Lapierre MA, Brown AM, Houtzer HV et al. (2017) Childdirected and nutrition-focused marketing cues on food packaging: links to nutritional content. Public Health Nutr 20, $765-773$. 
38. Kanter R, Reyes M \& Corvalán C (2017) Photographic methods for measuring packaged food and beverage products in supermarkets. Curr Dev Nutr cdn. 117.001016, http://cdn.nutrition.org/content/early/2017/09/13/cdn.117. 001016

39. Eldesouky A, Pulido A \& Mesias F (2015) The role of packaging and presentation format in consumers' preferences for food: an application of projective techniques. J Sens Stud 30, 360-369.

40. Gantz W, Schwartz N, Angelini JR et al. (2007) Food for Thought: Television Food Advertising to Children in the United States. Menlo Park, CA: Kaiser Family Foundation.

41. Harris JL, Sarda V, Schwartz MB et al. (2013) Redefining 'child-directed advertising' to reduce unhealthy television food advertising. Am J Prev Med 44, 358-364.

42. Hawley KL, Roberto CA, Bragg MA et al. (2013) The science on front-of-package food labels. Public Health Nutr 16, 430-439.

43. Hebden L, King L \& Kelly B (2011) Art of persuasion: an analysis of techniques used to market foods to children. I Paediatr Child Health 47, 776-782.

44. Hieke S \& Newman CL (2015) The effects of nutrition label comparison baselines on consumers' food choices. J Consum Aff 49, 613-626.

45. Kim H, Lee D, Hong Y et al. (2016) A content analysis of television food advertising to children: comparison low and general-nutrition food. Int J Consum Stud 40, 201-210.

46. Koenigstorfer J, Groeppel-Klein A, Kettenbaum M et al. (2013) Eat fit. Get big? How fitness cues influence food consumption volumes. Appetite 65, 165-169.

47. Koenigstorfer J, Wasowicz-Kirylo G, Stysko-Kunkowska M et al. (2014) Behavioural effects of directive cues on frontof-package nutrition information: the combination matters! Public Health Nutr 17, 2115-2121.

48. Lauricella S \& Koster K (2016) 'Refueling' athletes: social media's influence on the consumption of chocolate milk as a recovery beverage. Am Commun J 18, issue 1, available at http://ac-journal.org/journal/2014-2017/Vol18/Issue\% 201/ACJ\%202016\%20Issue\%201\%20Article\%202.pdf

49. Levin AM \& Levin IP (2010) Packaging of healthy and unhealthy food products for children and parents: the relative influence of licensed characters and brand names. J Consum Behav 9, 393-402.

50. Machiels CJ \& Karnal N (2016) See how tasty it is? Effects of symbolic cues on product evaluation and taste. Food Qual Prefer 52, 195-202.

51. Moon YS (2010) How food ads communicate 'health' with children: a content analysis of Korean television commercials. Asian J Commun 20, 456-476.

52. Otten JJ, Hekler EB, Krukowski RA et al. (2012) Food marketing to children through toys: response of restaurants to the first US toy ordinance. Am J Prev Med 42, 56-60.

53. Page RM \& Brewster A (2007) Emotional and rational product appeals in televised food advertisements for children: analysis of commercials shown on US broadcast networks. J Child Health Care 11, 323-340.

54. Freelon D (2010) Intercoder reliability calculation as a web service. Int J Internet Sci 5, 20-33.

55. Neuendorff KA (2002) The Content Analysis Guidebook. Thousand Oaks, CA: SAGE Publications, Inc.

56. Grigsby-Toussaint DS, Moise IK \& Geiger SD (2011) Observations of marketing on food packaging targeted to youth in retail food stores. Obesity (Silver Spring) 19 $1898-1900$

57. Hawkes C (2010) Food packaging: the medium is the message. Public Health Nutr 13, 297-299.

58. Chacon V, Letona P \& Barnoya J (2013) Child-oriented marketing techniques in snack food packages in Guatemala. BMC Public Health 13, 967.

59. Livingstone $S$ \& Helsper EJ (2006) Does advertising literacy mediate the effects of advertising on children? A critical examination of two linked research literatures in relation to obesity and food choice. J Commun 56, 560-584.

60. Roedder DL (1981) Age differences in children's responses to television advertising: an information-processing approach. J Consum Res 8, 144-153.

61. Chandon P \& Wansink B (2012) Does food marketing need to make us fat? A review and solutions. Nutr Rev 70, 571-593.

62. Glanz K, Bader MD \& Iyer S (2012) Retail grocery store marketing strategies and obesity: an integrative review. $\mathrm{AmJ}$ Prev Med 42, 503-512.

63. Legault L, Brandt MB, McCabe N et al. (2004) 2000-2001 food label and package survey: an update on prevalence of nutrition labeling and claims on processed, packaged foods. J Am Diet Assoc 104, 952-958.

64. Mayhew AJ, Lock K, Kelishadi R et al. (2016) Nutrition labelling, marketing techniques, nutrition claims and health claims on chip and biscuit packages from sixteen countries. Public Health Nutr 19, 998-1007.

65. Abrams KM, Evans C \& Duff BR (2015) Ignorance is bliss. How parents of preschool children make sense of frontof-package visuals and claims on food. Appetite 87, 20-29.

66. Andrews JC, Burton S \& Netemeyer RG (2000) Are some comparative nutrition claims misleading? The role of nutrition knowledge, ad claim type and disclosure conditions. J Advert 29, 29-42.

67. Sundar A \& Kardes FR (2015) The role of perceived variability and the health halo effect in nutritional inference and consumption. Psychol Mark 32, 512-521.

68. Schuldt JP (2013) Does green mean healthy? Nutrition label color affects perceptions of healthfulness. Health Commun 28, 814-821.

69. Heller R, Martin-Biggers J, Berhaupt-Glickstein A et al. (2015) Fruit-related terms and images on food packages and advertisements affect children's perceptions of foods' fruit content. Public Health Nutr 18, 2722-2728.

70. Gill JMR \& Sattar N (2014) Fruit juice: just another sugary drink? Lancet Diabetes Endocrinol 2, 444-446.

71. Sütterlin B \& Siegrist M (2015) Simply adding the word 'fruit' makes sugar healthier: the misleading effect of symbolic information on the perceived healthiness of food. Appetite 95, 252-261.

72. Bialkova S, Grunert KG \& van Trijp H (2013) Standing out in the crowd: the effect of information clutter on consumer attention for front-of-pack nutrition labels. Food Policy 41, 65-74.

73. Gunter B (2016) Kids and Branding in a Digital World. Manchester: Manchester University Press.

74. Schneider W \& Pressley M (2013) Memory Development Between Two and Twenty. New York: Psychology Press.

75. Federal Trade Commission (2008) Marketing Food to Children and Adolescents: A Review of Industry Expenditures, Activities, and Self-Regulation. Washington, DC: Federal Trade Commission.

76. Nestle M \& Ludwig DS (2010) Front-of-package food labels: public health or propaganda? JAMA 303, 771-772. 